\title{
LA LÍRICA DE LA RESISTENCIA EN TAMBORES EN LA NOCHE DE JORGE ArTEL*
}

\author{
The Lyrics of Resistance in Tambores en \\ la noche by Jorge Artel
}

Romuald-Achille Mahop Ma Mahop ${ }^{1}$

* Cómo citar este artículo: Mahop Ma Mahop, R. A. (2020). La lírica de la resistencia en Tambores en la noche de Jorge Artel. Estudios de Literatura Colombiana 47, pp. 15-36. DOI: https://doi.org/10.17533/ udea.elc.n47a01

1 https://orcid.org/0000-0002-4047-8127 mahorom2006@yahoo.fr Université de Yaoundé I, République du Cameroun
Editores: Andrés Vergara Aguirre, Christian Benavides Martínez, Valentina Noreña Gómez

Recibido: 25.01 .2020

Aprobado: 09.05.2020

Publicado: 23.06.2020

Copyright: (C2020 Estudios de Literatura Colombiana. Este es un artículo de acceso abierto distribuido bajo los términos de la Licencia Creative Commons Atribución No comercial - Compartir igual 4.0 Internacional
Resumen: este artículo explora los mecanismos de construcción textual de la resistencia afrodescendiente que el colombiano Jorge Artel despliega en su libro Tambores en la noche. Intento mostrar que la reivindicación de la identidad negra en Jorge Artel se logra mediante la obstinada memoria del pasado, la reapropiación orgullosa de la herencia biológica y la resistencia ante las fuerzas amnésicas o cualquier otra estrategia de distorsión. El trabajo subraya así la actualidad de la obra arteliana que coincide con la persistencia de cuestiones raciales en las agendas sociales, políticas y culturales de las naciones latinoamericanas contemporáneas.

Palabras clave: poesía afrocolombiana; Jorge Artel; identidad; resistencia; memoria.

\begin{abstract}
This essay explores the mechanisms of textual construction of the Afrodescendant resistance in Tambores en la noche, a collection of poems by the Colombian writer Jorge Artel. I try to show how the persistent memory of the past, the proud lyrical reappropriation of the biological legacy, and the struggle against the policy of amnesia or any other strategy of distortion are key instruments for Artel's claim for a more integral negro racial identity. Thereby, the work thereby underlines the topicality of Artel's lyrical work which coincides with the persistence of racial issues in the social, political and cultural agendas of the contemporary Latin American nations.
\end{abstract}

Keywords: Afro-Colombian poetry; Jorge Artel; identity; resistance; memory. 
I was a red man one time,

But the white men came.

I was a black man, too,

But the white men came.

They drove me out of the forest.

They took me away from the jungles.

I lost my trees.

I lost my silver moons

(Langston Hughes, “Lament for Dark People”)

La irrupción desde finales del siglo $\mathrm{xx}$ en el escenario historiográfico y literario colombiano del concepto de "literatura afrocolombiana" ha permitido que hoy en día, unas pocas décadas después, la expresión se haya convertido en una verdadera categoría de análisis, con una frecuencia de empleo creciente en la crítica literaria que parece implicar tácitamente su legitimidad. Algo similar ocurre con el concepto de "diáspora africana"1 que se ha impuesto en el lenguaje crítico y teórico desde la segunda mitad del siglo xx. Si bien puede sorprender el interés por la literatura afrocolombiana, habida cuenta de que, durante buena parte de dicho siglo, la literatura negra de Colombia no había gozado de un estatus académico en el país (Valero, 2015a, p. 10), esta nueva atención crítica se debe quizá a agendas políticas y a dinámicas sociales e intelectuales contrahegemónicas que consideran urgente subrayar la contribución negra en la edificación de las sociedades y culturas latinoamericanas contemporáneas. Conviene recordar en este sentido que, en términos estadísticos y según datos recogidos por Michel J. LaRosa y Germán Mejía (2013) en su Historia concisa de Colombia (1810-2013), "Colombia constituye el tercer país en América con mayor población de ancestro africano, después de los Estados Unidos y Brasil" (p. 53). Esta importante presencia afrodescendiente explica asimismo la inclusión de las problemáticas relacionadas con la cultura afro en las agendas políticas del país. Buena muestra de ello es que, con ocasión de la conmemoración del bicentenario de las Independencias en el año 2010 en Colombia, el área de literatura del Ministerio

1 Silvia Valero (2015b) traza la evolución de este concepto, marcando como hito del inicio de su generalización crítico-teórica la segunda mitad del siglo xx, a través de una tentativa de designar a "grupos de descendientes de africanos en el mundo”. Aunque el término estaba ya presente desde los años 50 entre los estudiosos, fue en el Congreso Internacional de Historiadores de África en Dar es Salaam en 1965 donde se marcó el principio de la consagración de su empleo como categoría analítica. Los estudiosos separan en principio la concepción afrodiaspórica, tal como se da desde los 60 y 70, de la que predomina en las décadas anteriores. Antes de los 60 , apunta Valero, la diáspora africana se concebía sobre todo en un sentido racial y genético, procedente de las teorías de Marcus Garvey, mientras que las teorías de la segunda mitad del siglo xx privilegiaron más bien una concepción diaspórica donde predominan factores de agrupación histórica y los vínculos culturales (pp. 86 y ss.). 
colombiano de Cultura financió en su totalidad la publicación de una serie de obras de literatura afrocolombiana. El proyecto coincidía además con el comienzo de la realización del llamado "Programa de Memoria Afrocolombiana" que se inscribe en una dinámica nacional de reconocimiento, valoración y promoción de la igualdad de oportunidades en beneficio de la población negra de este país de América. Uno de los autores cuya obra mereció una reedición fue el poeta afrodescendiente Jorge Artel (1909-1994), de verdadero nombre Agapito de Arcos, considerado como la voz preeminente de la expresión negra en la Colombia contemporánea (Prescott, 2000, p. 14). Su poemario fundamental Tambores en la noche (1940) no es solo una de las propuestas más llamativas de la resistencia ${ }^{2}$ cultural afrodescendiente en el espacio afrocaribeño, sino también una de las más actuales, a pesar de que, desde su edición príncipe de 1940, el libro ya tiene 80 años. El presente estudio intenta releer a Artel desde su contexto histórico y nuestros días, para subrayar la pervivencia de su defensa poética de la resistencia cultural negra, una empresa de memoria y la reivindicación de un estatus social propuestas que continúan vigentes. Al asociar aquí creación poética y resistencia, estoy planteando que Artel escribe desde una sociedad que mira su trabajo como oficio de subalterno, lo cual le empuja a alzarse primero contra un sistema que busca uniformizar la cultura sobre la base de una determinada interpretación de la historia y de las peculiaridades físicas de los seres humanos. Su obra se plantea como la propuesta de una mirada alternativa y de una relectura del pasado frente a los desafíos del presente. Desde el punto de vista teórico, mi trabajo sigue las tesis de Astrid Erll (2012) acerca de la literatura como lugar de la memoria ${ }^{3}$ así como los planteamientos de Manuela Avendaño-Ramírez y Juan David Villa-Gómez (2017). Para estos estudiosos, el arte constituye un medio de resistencia contra los recursos de la fosilización y permite enlazar la experiencia del pasado con el presente y el porvenir en una sociedad que trata

2 Este concepto me resulta pertinente a la hora de abordar las prácticas culturales de las minorías diaspóricas en las sociedades contemporáneas. En el caso específico de Jorge Artel en el Caribe colombiano, Graciela Maglia Vercesi (2005) habla de una "resistencia letrada" en virtud de la cual el poeta se vale de los determinismos inherentes a la sociedad caribeña racializada en la que Artel está inmerso: "el locus de enunciación de Jorge Artel tiene como referente la cultura letrada, preeminente en el periodo colonial de América hispánica, especialmente en Colombia. Artel responde a la ideología republicana y nacional y la identidad blanca, criolla. Desde esa voz, intenta legitimar la oralidad propia de su etnia frente a la cultura escrituraria del país, no es un gesto de blanqueamiento, sino de recuperación o re-apropiación de las raíces” (p. 84).

A lo largo de este estudio, emplearé este concepto desde la perspectiva de los desarrollos teóricos de Pierre Nora (2008) en torno a los lugares de la memoria y a los de Astrid Erll (2012). Erll explica que los textos literarios "cumplen diversas funciones en la cultura del recuerdo como, por ejemplo, formar representaciones sobre mundos pasados, transmitir imágenes de la historia, negociar las competencias del recuerdo y reflexionar sobre procesos que lleva a cabo la memoria colectiva y los problemas que enfrenta" (p. 197). La literatura y la memoria llegan a crear sentido al proporcionar "versiones de la realidad y del pasado" mediante "procesos de condensación, los cuales son significativos para la creación y la transmisión de representaciones precisas del pasado” (p. 198). 
de exorcizar el ayer. De acuerdo con Avendaño Ramírez y Villa-Gómez (2017), aunque las manifestaciones del arte "no son expresiones de un proceso que implique acciones jurídicas o responsabilizantes, son escenario de transmisión de sentidos y develación de relatos, manifestaciones de lo nombrado y lo no dicho" (p. 509). Por tanto, "el arte y los modos performativos son formas alternativas y eficaces de ejercer resistencia, confrontar y transformar relatos dominantes" (p. 520). Antes de abordar la poesía de Artel, quisiera comenzar por situarla en su contexto histórico y nacional.

\section{Jorge Artel y la tradición lírica afrocolombiana}

Las figuras de Jorge Artel y la del poeta decimonónico Candelario Obeso son hoy en día consideradas como referentes ineludibles de la poesía afrocolombiana de los siglos xIx y xx. Pero de ahí a incluirlos en el marco más general de la literatura colombiana, hay un trecho todavía perceptible. Atento a esta carencia, Nicolay Vargas (2005) apela al "surgimiento de una nueva historia de la literatura colombiana", consciente de que, si bien "Jorge Artel y Candelario Obeso no dejan de ser nombrados en algunas historias, la literatura colombiana adolece [sic] de un trabajo para la literatura afrocolombiana"(p.129). Laurence E. Prescott (2000) apunta en este sentido que el nombre de Artel es notoriamente ausente en los estudios sobre poesía colombiana contemporánea. Además, los críticos de literatura hispanoamericana suelen considerarle como un mero epígono de los más célebres negristas afrohispanoamericanos, desatendiendo la singularidad de su contribución como poeta en el contexto específico colombiano (p. 14). Como indica Graciela Maglia Vercesi (2005), la voz de Artel "canta desde la periferia costera en un país centralizado cuyo nomos capitalino consagra el canon y rechaza la alteridad" (p. 86). Este hecho explica probablemente que Artel tratara de adaptar de alguna manera su oficio creador a los hábitos verbales en vigor, lo cual explica los resabios neoclásicos y el tono solemne y a menudo hímnico que distingue Maglia Vercesi en sus versos (p. 86).

A la falta de atención crítica que rodeó durante mucho tiempo la obra de Artel, hay que añadir las dificultades inherentes al estatus social del escritor afrocolombiano durante los siglos xIx y buena parte del xx. Esto lo explica Prescott (2000) cuando recuerda que, desde los tiempos de Candelario Obeso a los de Artel, el escritor afrocolombiano, como el resto de la familia a la que pertenece, están atrapados en las penurias propias del peldaño que les corresponde: el más bajo de la jerarquía social. El escritor negro 
tiene que realizar esfuerzos considerables para educarse y publicar sus libros (p. 58). Tal fue el contexto de Artel. Los condicionamientos de su época impidieron sin duda que el poeta dejara al mundo más obras de las que hoy tenemos de él. Ni mencionemos la mirada social despectiva de aquellos que se extrañaban de que un negro pudiera ser poeta (Prescott, 2000, p. 70). En una palabra, a Jorge Artel no le resultó fácil asumir su herencia negra y la vocación poética en una sociedad todavía gobernada por prejuicios reductores.

A pesar de estos escollos, Artel siguió fiel a su vocación literaria y puede que la elección del título "tambores en la noche" encierre una rebeldía, un acto de desafío al sistema establecido. En tal caso, si el signo "noche" sugiere quietud, calma y reposo, los "tambores" funcionan como la turbación insurreccional de este orden cósmico que, en tal interpretación, sirve de metáfora al orden social. En este sentido, la obra de Artel participa del juego de "tensiones” del que habla Marcelo José Cabarcas Ortega (2013) cuando apunta que la literatura afrocolombiana es tan solo una muestra de las "tensiones y negociaciones, concesiones y reconfiguraciones" (p. 74) que ponen en tela de juicio lo canónico. Tal hecho se cumple en nuesro poeta, a quien la crítica sitúa generacionalmente dentro del grupo de poetas colombianos de habla castellana entre los cuales destaca la llamada "Generación del 27" (Ocampo Zamorano y Cuesta Escobar, 2010, p. 23). Junto a otros poetas afrodescendientes hispanoamericanos como el cubano Nicolás Guillén o el puertorriqueño Luis Palés Matos, Artel ha contribuido a enriquecer la poesía de su país a través de una sensibilidad profundamente caribeña en la cual se transparenta el bagaje negroafricano, cuyos acentos han sido reconocibles en destacables precursores nacionales y afroamericanos. Gabriel Ferrer Ruiz (2010) ha indicado en este sentido en qué medida la obra lírica de Artel bebe de la fuente de otro clásico decimonónico afrocolombiano: Candelario Obeso (1849-1884). Sin embargo, a diferencia de este padre fundador de la poesía negra de Colombia, Artel elimina de su proceso creador la mirada estereotipada que lastraba la poética de sus antecesores, para promover, más bien, una tradición "afrocolombiana" ${ }^{4}$ acorde con las preocupaciones esenciales, repercutidas líricamente mediante las apetencias expresivas del verso libre.

Soy consciente de cometer un abuso conceptual ya que, en verdad, la obra de Candelario Obeso, enmarcada en la Colombia decimonónica, es cronológicamente anterior a los debates nacionales e internacionales que han consagrado recientemente la expresión "literatura afrocolombiana". Como indica al respecto Silvia Valero (2013, p. 16), en Colombia, el término "afrocolombiano" surge alrededor de los años 50 del siglo xx, coincidiendo con los inicios de los estudios antropológicos, mientras que Candelario Obeso se desenvolvió más bien en el contexto de la Colombia decimonónica. El mismo abuso consciente preside el empleo de la expresión "afrodescendiente" aplicada a Jorge Artel, ya que también surge tal concepto en las últimas décadas. 
Entre las problemáticas que atraviesan la obra de Artel destacan la experiencia histórica de la esclavitud, la identidad del sujeto de raza negra, su situación social, política y cultural en una sociedad colombiana plural. Ferrer Ruiz (2010) indica a este respecto que el elemento negro se hace presente en Colombia a lo largo de procesos sociales, históricos, políticos y culturales que repercuten en la literatura, apreciables a través de motivos como "la nostalgia de la tierra, la rebeldía ante la condición social impuesta, las creaciones folclóricas, los cantos de trabajo desesperados, los Negro Spirituals, los cantos de esperanza que surgieron en las plantaciones en los días de la esclavitud" (p. 12). Respecto a la poesía afrocolombiana anterior a Artel, la lírica de este último deja filtrar una sensación de novedad que surge no solo de la incorporación de rasgos formales y cuestiones nacidas de la situación de los negros en Colombia, sino también de la superación de la visión exótica que a menudo se observa en el negrismo anterior. Uno de los poemas fundamentales de Tambores en la noche, el extenso texto titulado "Poema sin odios ni temores", rechaza precisamente todo arte para turistas o circo, y deja en claro que la voz que se alza en cada poema surge de las honduras de un ser consciente de las trabas que la sociedad trata de imponerle como una camisa de fuerza:

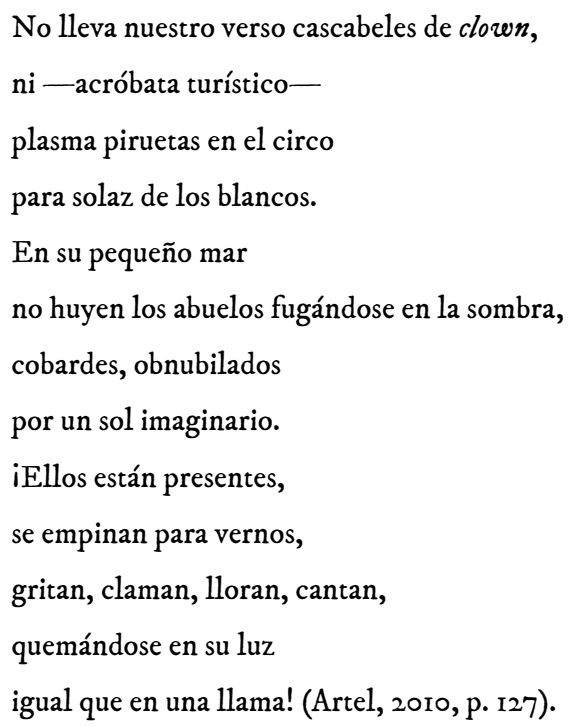

Al repudiar un arte para distraer al público con acrobacias de circo "para solaz de los blancos", Artel se hace partidario de una literatura de resistencia, el adalid de un 
"afro-centrismo", tal como lo defiende Molefi Kete Asante (2003), ${ }^{5}$ que solo en la negación de la superficialidad y los estereotipos logrará alcanzar el estatus de arte serio y verdaderamente representativo de la conciencia negra. Tal fue la empresa de restitución que el poeta de Cartagena de Indias intentó llevar a cabo en Colombia, al promover la voz afrocolombiana a través de una serie de problemáticas que distaban claramente de los derroteros creativos del grupo Piedra y Cielo, que seguía moviéndose esencialmente dentro de los cauces neorrománticos y modernistas de aquellos años cuarenta. Escribir entraña en este caso un deber que se cumple en el acto de la memoria, convencido Artel de que solo en la resurrección simbólica de las sombras de ayer, representadas en el fragmento citado por estos "abuelos" que "se empinan para vernos", se logrará un adecuado enraizamiento del afrocolombiano en el presente. Así se cumple precisamente la necesaria sacralización que se opera en el trabajo de la memoria, instancia siempre amenazada por "el criticismo destructor" de la historia (Nora, 2008, p. 21).

\section{Una asunción lírica de la herencia racial}

A lo largo de Tambores en la noche se percibe una tendencia general del hablante lírico a asumir su herencia afro. Algunas composiciones incluso parecen inspiradas por el retorno físico del poeta a tierras africanas como en pos de un abolengo cuyas raíces se sospechan vivas, pero difíciles de fijar con nitidez en las vicisitudes de la reconfiguración política de los antiguos reinos del África. Vuelta ilusoria, vieja manifestación de una visión romántica (Gilroy, 2014) o recurso simbólico, lo cierto es que tal visión textual del origen adquiere en la poesía de Artel un carácter militante en la medida en que declara un orgullo de los orígenes. Tal actitud se transparenta en la puesta en evidencia desde el título del libro de uno de los elementos emblemáticos de la cultura negroafricana: el tambor. Al reunir en él sus composiciones, el poeta enfatiza la perdurabilidad de la civilización negroafricana más allá de sus límites geográficos naturales. De hecho, el tambor siempre ha estado presente en la vida

En L'Afrocentricité, Asante (2003) considera que los pilares de la hegemonía blanca sobre los negros se han edificado a partir de una fábula que ya no escapa a nadie. Para él, los blancos no son más que expertos en propaganda que se valen de todo tipo de recursos para extender sus ideas a partir de diferentes medios culturales como las películas, los libros, las imágenes o la música. Logran así transmitir una sensación de unidad y de evidencia de su cultura y de su ideología (p. 4). A estos recursos hay que añadir igualmente la labor ideológica de la historiografía. La pregunta de Asante que busca esclarecer a quién pertenece la historia y la cultura que sirven de norma (p. 12) invita a dudar de los conocimientos habitualmente presentados por Occidente como hechos históricos incuestionables. 
social de los pueblos negros, en sus actividades rituales y sus creaciones musicales. Como señala Ferrer Ruiz (2010), por un lado, "la música, especialmente la percutiva, es un aspecto mediante el cual, desde la Colonia, la raza negra se autoidentificaba y se hacía reconocer ante los demás" (p. 25). Por otro lado, el toque del tambor "abre puertas a los espacios donde moran los antepasados”(p. 25). De acuerdo con Jenny González Muñoz (2010), "Los tambores, en sus diversas manifestaciones, son empleados en variadas funciones relacionadas con los ritos sagrados de origen africano como el candomblé, la macumba, el lucumi o el vaudou" (pp. 21-22). Gracias al ritmo de los tambores "las deidades danzan y consiguen su presencia en las tierras americanas velando a través del médium por la vida de sus hijos africanos. Una muestra significativa de resistencia afrodescendiente, africana o afroamericana, es precisamente este apego” (p. 22). De ahí que no resulta sorprendente que en el poema "Soneto más negro" el tambor intervenga como acompañamiento fundamental en un ritual vudú:

\footnotetext{
iTambor, lágrima errante, a la deriva!

Conjuro voduísta del Caribe, tu alma torturada y sensitiva se pierde en el silencio que la inhibe.

Desde el trasfondo oceánico, intuitiva, mi dársena sonora te percibe y me llega tu luz mucho más viva y es más negro el soneto que se escribe.
}

Febril impulso tu hontanar eleva, en proceloso vértigo me lleva hacia pueblos hundidos en la sombra, donde vierten los cánticos su oscura emanación de hechizo y de locura sobre una voz remota que me nombra (Artel, 2010, p. 97).

Las dos bases de la cultura afro de Artel se dan la mano en esta composición: la negroafricana, por un lado, y la caribeña, por otro. La imagen del tambor como 
"lágrima errante" posee a primera vista resonancias vanguardistas, por la atrevida asociación de elementos dispares —el tambor y la lágrima-. Aun así, parece más legítimo considerar tal imagen como una personificación del tambor que, entendido como símbolo afro, recrea más bien junto con el epíteto "errante”, el motivo de la diáspora. El tambor que llora simboliza a los africanos deportados hacia latitudes extrañas y forzados a vivir con la cicatriz de esta herida que los siglos de trauma han ocasionado. El ritual vudú que el hablante lírico sitúa explícitamente en el espacio afrocaribeño conjura esta larga hemorragia y se recurre por ello a la "oscura / emanación de hechizo y locura" de "los cánticos" negros. Dichas bases se funden en la ritualidad del culto vudú. La interpretación que hago del título entero de Artel no dista de esta perspectiva cultural: se trata de la expresión de una comunicación musical, emocional y mística del poeta con la memoria inexpugnable de los antepasados negros que sobreviven en el tiempo y que, gracias a la ritualidad originaria, atraviesan el espacio entre la patria de antaño y la tierra impuesta por la contingencia histórica. El toque del tambor nocturno es el vehículo de este proceso místico en el cual las fuerzas ocultas terráqueas abolen los determinismos espaciotemporales del mundo diurno para restaurarle al induviduo, custodiado por la sombra, su equilibrio de cuerpo y espíritu. En esta fusión del ser humano con el universo, del tambor con las manos que lo tocan, no media ya ninguna distancia, como lo expresa en admirable símil el poeta en el texto epónimo "Tambores en la noche":

Los tambores en la noche

son como un grito humano.

Trémulos de música les he oído gemir, cuando esos hombres que llevan

la emoción en las manos

les arrancan la angustia de una oscura saudade, de una íntima añoranza, donde vigila el alma dulcemente salvaje de mi vibrante raza, con sus siglos mojados en quejumbres de gaitas (Artel, 2010, p. 57). 
Aparece aquí uno de los elementos que Prescott (2000) considera característicos de la cultura caribeña de Artel, el "grito" (p. 122) como comparación de los tambores nocturnos. Música y dolor se juntan en estos versos donde el toque de los tambores crea un doble ritmo: el de los bailarines y el de la rememoración melancólica cuya máxima expresión es la "oscura saudade". Una lectura apresurada del texto podría reducir las ideas expresadas en esta composición a una reproducción de clichés sobre lo afro. Con todo, tal lectura debe superarse en virtud de una recuperación militante de los tópicos, similar a la reinversión semántica que hicieron los poetas de la négritude al darle la vuelta al término despectivo nègre en el contexto francófono. ${ }^{6}$ Jean Paul Sartre (1948) ha advertido ese momento de rebeldía en el que el hombre nègre, acorralado por un sustantivo que le devolvía diariamente a los determinismos del pigmento, no tuvo otro remedio que abrazar insurreccionalmente la expresión: "Ainsi est-il acculé à l'authenticité: insulté, asservi, il se redresse, il ramasse le mot de "nègre" qu'on lui a jeté comme une pierre, il se revendique comme noir, en face du blanc, dans la fierté" (p. XIV).

Prescott (2000) explica que las primeras composiciones de Artel, al igual que las de Tambores en la noche, aspiran a otra dimensión de la realidad, escondida bajo las apariencias del júbilo de los cantos y la sensualidad de las danzas africanas (p. 98). En esta composición, los gemidos de los tambores nocturnos se acompasan al temple emocional de quienes los tocan. El sintagma "mi vibrante raza" sugiere a la vez la piel del tambor y la firmeza de la piel negra, mediante una asociación de imágenes que recuerda al Léopold Sédar Senghor de Chants d'ombre. ${ }^{7}$ Senghor (1956), uno de los mayores cantores del tambor en la lírica africana del siglo $\mathrm{xx}$ —como lo ilustran libros como Éthiopiques-, explica cómo muchos poetas gímnicos de su región de origen solían componer sus cantos solo bajo el hechizo del ritmo de los tambores (p. 159). El trance o embeleso ante el ritmo de los tantanes parece presidir de cabo a rabo la escritura de Tambores en la noche de Jorge Artel. Tanto es así que el poeta, cuyo interés

6 Acerca de esta expresión debo aclarar muy de paso que, en ámbitos hispánicos, el término "negro" tiene la virtud de ser la única verdadera opción corriente, procediendo directamente del étimo latino niger, nigri. En francés, en cambio, ante la copresencia del término de empleo corriente noir, la elección de nègre es necesariamente deliberada y, por tanto, no goza de la ambigüedad tranquilizadora del término negro en el contexto hispánico, el cual, como ya se ha dicho, puede encerrar a la vez a priori el matiz despectivo de nègre y el empleo "neutro" de noir.

$7 \quad$ En muchos textos de Chants d'ombre de Senghor (1945), la piel negra se asimila a la firmeza del tambor. Así, en el poema "Femme nue, femme noire", la belleza de la mujer negra es reforzada por la firmeza de su piel que el poeta metaforiza mediante el tambor: "Tamtam sculpté, tamtam tendu qui grondes sous les doigts du vainqueur" (p. 15) [Tam-tam esculpido, tam-tam tenso que truenas bajo los dedos del vencedor] (traducción propia). 
por el tema de la música ${ }^{8}$ coincide en este caso con el de Senghor, elabora lo que podría denominarse una mistica de los tambores, en composiciones donde este instrumento trasciende su ordinaria función musical para adquirir valores rituales cuya comprensión exige un profundo conocimiento de las sociedades negroafricanas. Uno de los textos arquetípicos del libro es, en esta vena lírica, "El lenguaje misterioso":

\author{
Surgen de la entraña nocturna \\ los tambores litúrgicos... \\ Un mundo elemental despierta \\ bajo el eco enronquecido \\ y entre resplandores de marfil \\ cada hoja recoge \\ la inmensidad de la tierra. \\ -iDum... dum... dum...! \\ ¿Quién puede adivinar el lenguaje sombrío \\ de estas llamadas \\ estremecidas de misterio?
}

Los tambores monótonos repiten:

-i... Dum... dum... dum...!

iLa noche conduce el trémolo

entre archipiélagos de árboles,

sobre océanos de silencio! (Artel, 2010, p. 94).

Aquí, los golpes del tambor resuenan con ecos cargados de misterio en la noche. Sus retumbos hacen surgir de la sombra "un mundo elemental" cuyo "lenguaje sombrío" trata de adivinar el hablante lírico. Nos encontramos ante una tentativa por reconstruir el universo ritual negroafricano y reafirmar la pervivencia de las bases ontológicas del

8 Se ha señalado con frecuencia el sitio de honor que la música ocupa en la lírica afroamericana en general. Jorge Artel no escapa a esta regla y la región colombiana en la que transcurrió su existencia no lo desmiente. Sergio Andrés Sandoval (2011) explica que, "como afirmación étnica y estética, la poesía de la costa Caribe en Colombia ha tejido en sus versos un contexto que surge de las raíces culturales. La tradición literaria de poetas como Candelario Obeso, Jorge Artel y Juan Zapata Olivella no se encuentra únicamente en la escritura, sus fuentes primordiales son la música y la tradición oral que impregnan sus libros de una vitalidad y voz propias. Ritmos como el bullerengue, la cumbia, el porro, la gaita y el lumbalú están presentes en la obra de estos poetas como herencias vivas de la sangre africana que afirmaron con plenitud" (pp. 204-205). 
sujeto negro más allá de los accidentes de la historia. Ayleen Julio Díaz (2009) ha explicado en este sentido que "la presencia del tambor va marcando no solo la presencia negra, sino ese deseo del yo lírico-poeta de tener contacto con lo que considera su madre patria, África” (p. 97). Esta perspectiva cultural se refuerza aún más en la dedicatoria del poemario entero: “a mis abuelos, los negros”. La puesta en evidencia del linaje negro desde el quicio del poemario ya lo dice todo: la mano que escribe asume de entrada como incuestionables sus fuentes africanas mediante la figura de los abuelos, interesante coincidencia de tema y perspectiva con una de las composiciones de Nicolás Guillén titulada precisamente "El abuelo", incluida en Las grandes elegias y otros poemas. Desde el inicio del poemario de Artel, la adhesión a la identidad negra es rotunda:

Negro soy desde hace muchos siglos.

Poeta de mi raza, heredé su dolor.

Y la emoción que digo ha de ser pura

en el bronco son del grito

y el monorrítmico tambor (Artel, 2010, p. 49).

El primer verso postula una pervivencia plurisecular del yo lírico como modo de colectivización del discurso poético. El yo textual parece hablar desde una base afrocéntrica en la que lo negro apunta a una categoría ${ }^{9}$ reconocible y claramente discernible de las demás razas. Desde el segundo verso, el poeta confirma esta postura al considerarse a sí mismo como portavoz y cantor de su raza, heredero de su dolor. El acto poético no está visto aquí como un juego vano de bellos sonidos, sino como la expresión de un dolor real, de modo que la escritura es una tentativa por verbalizar la emoción que surge como "pura”, "en el bronco son del grito / y el monorrítmico tambor". Semejante "grito", expulsado de un corazón doliente, encuentra entonces en el tambor su eco; pero al mismo tiempo, esta reverberación repercute también las voces milenarias de los antepasados: "El hondo, estremecido acento / en que trisca la voz de los ancestros, / es mi voz" (p. 49). Hay en los poemas de Artel un notorio esfuerzo por afirmar una y otra vez como asideros culturales imprescindibles el sustrato racial africano, reconstruido textualmente no solo por la evocación de los antepasados negros, sino también por la vuelta simbólica al espacio africano de origen. Así, en la composición "La voz de los diferencias étnicas inmutables" (p. 14). 
ancestros", el ambiente marítimo y caribeño se deja contagiar pronto con reminiscencias gratas y dolorosas del imaginado pasado en África:

Oigo galopar los vientos

bajo la sombra musical del puerto.

Los vientos, mil caminos ebrios y sedientos,

repujados de gritos ancestrales,

se lanzan al mar.

Voces en ellos hablan

de una antigua tortura,

voces claras para el alma

turbia de sed y de ebriedad (Artel, 2010, p. 50).

Los datos que se refieren al presente de la situación de enunciación ubican al yo lírico en un ambiente de ciudad litoral mediante referencias situacionales tales como "los vientos", "la sombra musical del puerto" o el "mar". A este espacio real e inmediato se superpone otro, mítico, mnemónico y obsesivo, presto a resurgir bajo el silbido del viento y marcado por "gritos ancestrales" y esas "voces" que cuentan "una antigua tortura”, referencia inequívoca a los avatares de la deportación y de la esclavitud. A continuación, la pregunta que interroga sobre la naturaleza de la persistente angustia busca una respuesta que solo se halla en la espiral de la historia donde está el hombre negro condenado a revivir las mismas vejaciones y la misma incomprensión:

¿De qué angustia remota será el signo fatal

que sella en mí este anhelo

de claves imprecisas?

Oigo galopar los vientos,

sus voces desprendidas

de lo más hondo del tiempo

me devuelven un eco

de tamboriles muertos,

de quejumbres perdidas

en no sé cuál tierra ignota,

donde cesó la luz de las hogueras

con las notas de la última lúbrica canción (Artel, 2010, p. 50). 
Los tres primeros versos sintetizan bajo la forma de una interrogación las dudas que asaltan al personaje poemático. Si en apariencia el poeta deja entender que no acierta a definir el origen de sus inquietudes, los versos siguientes demuestran que solo se trata de una interrogación retórica. De hecho, la "angustia remota", las "voces desprendidas / de lo más hondo del tiempo", ese "eco / de tamboriles muertos, / de quejumbres perdidas / en no sé cuál tierra ignota" no son sino nostálgicas evocaciones de África. Más adelante ocurre una mitificación de los datos inmediatos en virtud de la cual el presente se conecta de repente con el pasado remoto en una cosmovisión temporal cíclica que permite asimilar las vejaciones de hoy con las de ayer. Así, la mirada que escruta el puerto ya no ve en los barcos actuales objetos del presente, sino reiteraciones cíclicas de aquellas naves negreras que trajeron a los antepasados:

\author{
Mi pensamiento vuela \\ sobre el ala más fuerte \\ de esos vientos ruidosos del puerto, \\ y miro las naves dolorosas \\ donde acaso vinieron \\ los que pudieron ser nuestros abuelos (Artel, 2010, p. 51).
}

Conviene señalar un detalle enunciativo que me parece insoslayable en relación con esta asunción del pasado negro en la poesía de Jorge Artel. En la última estrofa de "La voz de los ancestros", el hablante lírico se autopresenta como "Jorge Artel", dejando así por sentada la identidad entre el sujeto lírico, en teoría ficticio, y el autor, instancia por definición real o empírica. Esta coincidencia onomástica entre la instancia lírica y la figura autorial se interpreta como una estrategia de validación de la sinceridad propuesta por el poeta en esta especie de pacto lírico-autobiográfico. En otros términos, el poeta quiere que aceptemos como auténticas las emociones y experiencias que nos va ofreciendo a lo largo de sus composiciones. $Y$ aquí hay que volver brevemente a esa vuelta física al espacio africano que ya anticipaba anteriormente. $\mathrm{Si}$ en los poemas anteriores el retorno parece principalmente simbólico, en otros, en cambio, el hablante lírico lo plantea como algo real. Así ocurre, por ejemplo, en el poema "Alto Congo": 
Yo voy por el alto Congo...

Diez negros

y un solo golpe en el agua.

Uno solo.

iCómo curva las espaldas

el ímpetu de los remos!

iQué brillantes y qué anchas!

Son de acero.

Yo voy por el alto Congo...

Un solo golpe en el agua.

Uno solo.

Verdes palmeras gigantes

esconden el sol a trechos.

Los hombres cantan y reman.

Brazzaville ya no está lejos (Artel, 2010, p. 95).

Desde el punto de vista enunciativo, el sujeto lírico presenta su viaje como algo en curso de desarrollo, incluyendo detalles como el bote, los remos y los remeros negros. La repetición del verso "Yo voy por el alto Congo" a lo largo de la composición refuerza este perspectiva durativa e inacabada. Además, el poema proporciona detalles de índole referencial que se aprecian en topónimos como el mismo río Congo o la ciudad de Brazzaville. El poema termina con la mención explícita de la posibilidad de que Congo haya podido ser la patria del poeta: “¿Qué grande es el alto Congo! / ¡Esta pudo ser mi patria / y yo uno de estos remeros!” (p. 95). La esperanza de encontrar las verdaderas raíces del linaje propio justifica la obsesiva presencia del personaje del abuelo a lo largo de la obra y refuerza el parangón ya mencionado con la poética de Nicolás Guillén. El poeta cubano sintetizó en su poema "El apellido" su sed de definir su identidad familiar remota. Artel está habitado por un ansia idéntica, representada por la constante referencia a los lejanos abuelos que pueblan sus poemas. Tal reivindicación de pertenencia a un linaje ancestral constituye uno de los pilares del cambio de perspectiva que Silvia Valero (2015a) percibe en la literatura afrodescendiente reciente respecto a las promociones anteriores. Para Valero, la representación literaria actual de lo afro muestra 1) "una política autoafirmativa de la 
subjetividad 'afrodescendiente', construida a partir de la idea de, 2) una comunidad traslocal unificada" (p. 13). Quince Duncan (2013) ha comparado el proceso de esta reivindicación en Artel y Guillén del siguiente modo: "En la poética de Guillén, al igual que en Artel, esa recuperación incluye todo. Y no se trata de folclores, de caricaturas o de simpatías paternalistas hacia el negro", sino más bien de la reivindicación de "la totalidad africana en su doble dimensión geográfica e histórica". Si hay un ideal de "comunidad ancestral africana" en la obra de nuestros dos poetas, esta "abarca toda África, todo territorio habitado por afrodescendientes, junto con sus hechos históricos, sus mitos, sus leyendas" (p. 8). Con todo, bien mirado, ¿qué representa esta reapropiación de la herencia negra sino una forma de resistencia del poeta ante las garras de un sistema secular que busca abolirla?

\section{Una poética de la resistencia}

Acaso todo poema no sea en definitiva más que la expresión de una resistencia, ya que las palabras que leemos tratan de perpetuar una herida, una dicha, una emoción, una extrañeza. No podemos apreciar cabalmente el fenómeno de la resistencia afroamericana en general en sus diferentes formas de expresión si olvidamos las severas restricciones que las estructuras administrativas coloniales y racistas impusieron a estas poblaciones. Para comenzar se debe admitir que la supervivencia de los elementos folclóricos o rituales del mundo negro constituye en sí misma una hazaña histórica, en un contexto en el que las expresiones culturales africanas estaban terminantemente prohibidas, a veces so pena de muerte, como se aprecia en el llamado Code Noir de 1685. Este código representa, según explica Daniel Jacobo-Marín (2010), "el fruto aciago del pensamiento racial del hombre blanco europeo y la culminación de un proyecto inhumano de grandes dimensiones de la poderosa nación francesa” (p. 34). A pesar de ello, en países como Haití, Cuba, Brasil, Venezuela, Panamá o Colombia, que fueron los principales territorios de supervivencia de los esclavizados negros, las danzas, las ceremonias rituales y los cantos de los negros pervivieron, especialmente en los palenques donde se reunían los esclavos fugitivos desde el siglo xvi (Barriga Monroy, 2012, p. 345). De ahí se desprende la insistencia en el papel de memoria y de supervivencia cultural africana que Artel asigna al tambor, verdadero puente percusivo y místico entre el espacio añorado y las nuevas tierras de supervivencia. 
Otra destacable forma de resistencia es aquella que se logra mediante cierta semantización del nivel lingüístico que busca transponer textualmente un modus vivendi, a través de la legitimación textual de opciones gráficas que mimetizan en el espacio poemático la oralidad del español afrocolombiano. En el primer caso, notamos que las reminiscencias que vuelven como epifanías de un ayer preexistente al trauma de la esclavitud brotan sin parar, al filo de la escritura a través de versos que bajo fórmulas diferentes dicen la misma verdad: el ayer como un latido constante desprendido del pasado se alza y persiste en el hoy, trayendo consigo una memoria de imágenes, lugares, seres y experiencias que el sujeto lírico mezcla con las intuiciones del mundo inmediato. Bien es cierto que esta actitud deriva, al decir de Gilroy (2014), de ciertas “concepciones románticas de la 'raza', el 'pueblo' y la 'nación”". Para colmo, prosigue Gilroy, "los temas de la nacionalidad, el exilio y la filiación cultural acentúan la fragmentación y la diferenciación ineludibles del sujeto negro" (p. 54). Si esto constituye uno de los riesgos del afrocentrismo más burdo, tampoco se debe perder de vista que en un poeta como Artel, la nostalgia no es una actitud pasiva, sino una especie de deber de memoria, una inmersión en referentes míticohistóricos necesarios a la construcción de una base identitaria de cara al presente y al futuro. Como dicen los versos del poema "La ruta dolorosa" de Artel (2010), "en la reminiscencia de una lágrima / residen nuestros dolores heredados". Si el poeta sigue distinguiendo en su propia voz "el tatuaje del látigo", sabe al mismo tiempo que solo en la cercanía fraternal, semejante a la que arropa a los bailarines, logrará que sea "trasmutada la cruz en el acento / de un grito liberado" (p. 99). La "añoranza de selvas" que percibimos en el poema "La cumbia" reviste un carácter militante, porque afirma precisamente el fracaso de los recursos amnésicos y la vivacidad de este pasado apreciable en la referencia a "un coro de voces vivas":

Oigo galopar los vientos,

sus voces desprendidas

de lo más hondo del tiempo

me devuelven un eco

de tamboriles muertos (Artel, 2010, p. 50).

Trota una añoranza de selvas

y de hogueras encendidas, 
que trae de los tiempos muertos

un coro de voces vivas (p. 55 ).

Las tentativas por arrasar la memoria antropológica del afrodescendiente fracasan una y otra vez ante la persistencia del pasado que viene a fundirse con el presente, dándole razón a Díaz (2009) cuando indica que "leer a Jorge Artel es, de cierta forma, unir el presente y el pasado" (p. 95). El "coro de voces vivas" que emerge del fondo de las edades revela el esfuerzo por redimir de la extinción programada y mantenida a lo largo de los siglos aquellas referencias imprescindibles. La voz de los tambores nocturnos actúa, pues, como una incitación a resistir las olas destructoras del olvido:

\author{
Los tambores en la noche, hablan. \\ iY es su voz una llamada \\ $\tan$ honda, $\tan$ fuerte y clara, \\ que parece como si fueran sonándonos en el alma! (Artel, 2010, p. 58 ).
}

La segunda forma de resistencia tiene que ver con una rebeldía que se expresa principalmente mediante el material lingüístico. Artel le tuerce el cuello al castellano normativo para que las prevaricaciones orales del español afrocolombiano se transparenten en el poema. Al incorporar el habla afrocaribeña, el poeta le confiere un estatus de legitimidad simbólica, como vimos en Maglia Vercesi (2005). Esta entrada de la oralidad local se aprecia en composiciones como "Sensualidad negra", "Bullerengue" o "El líder negro". Examinemos algunos fragmentos:

\footnotetext{
Si yo fuera tambó,

mi negra,

sonara na má pa ti.

Pa ti, mi negra, pa ti.

Si maraca fuera yo,

sonara solo pa ti.

Pa ti maraca y tambó,

pa ti, mi negra, pa ti.
} 


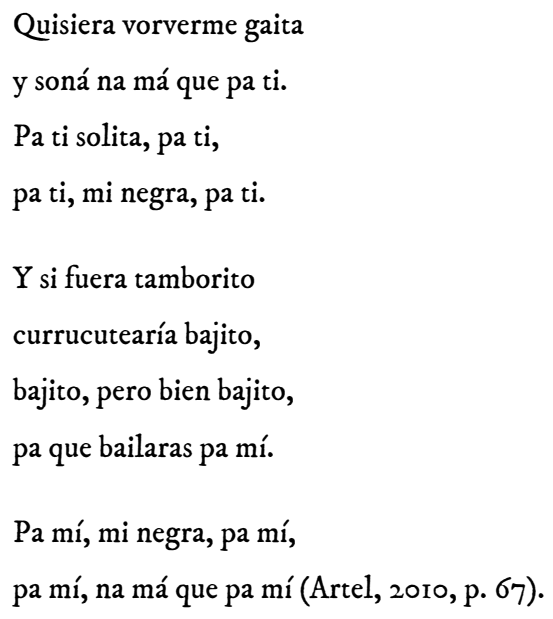

En Tambores en la noche, solo unos cuantos poemas parecen haber sido concebidos para dar cuenta de las posibilidades expresivas de la oralidad coloquial afrocolombiana, lo cual hace que el fenómeno revista en tales composiciones una destacada intencionalidad. Maglia Vercesi (2005) señala que "Artel tiene como referente la cultura letrada, preeminente en el período colonial de América hispánica, especialmente en Colombia” (p. 84). En otras palabras, nuestro poeta "canta desde una actitud reverencial y purista ante la lengua, herencia de la hispánica consideración del código lingüístico como un patrón inamovible" (p. 84). Esto implica que "desde esa voz, intenta legitimar la oralidad propia de su etnia frente a la cultura escrituraria del país, no en un gesto de blanqueamiento, sino de recuperación o re-apropiación de las raíces” (p. 84). En el caso del poema "Bullerengue", se trata de elevar a la categoría de poema un discurso en tono ligero que parece en principio brotar de una ejecución musical, de modo que la estructura rítmica de la composición poética sugiere los compases de ese ritmo, en consonancia con la avasalladora presencia musical ya referida en la obra de Artel. Distintos instrumentos de percusión están evocados a lo largo de la composición: tambor, tamborito, maraca, etc., bajo un telón de fondo amoroso. El propio título del poema designa un ritmo musical característico del departamento colombiano de Córdoba. Lo esencial del ritmo poético descansa en grupos binarios esencialmente yámbicos, más sistemáticos en los versos octosílabos dominantes en la mayoría de las estrofas. El poema "El líder negro" nos mantiene en este registro popular, pero elaborado esta vez en torno al elogio de un personaje público de ascendencia africana llamado "Diego Luî": 


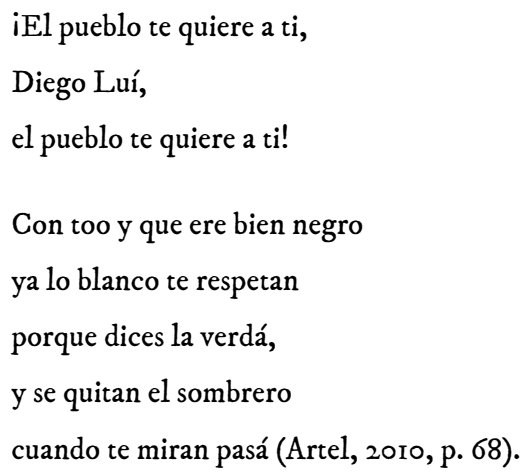

La dicción popular se aprecia no solo en la aspiración de ciertos sonidos consonánticos como ocurre con el fricativo $[s]$ en determinadas palabras (Lui, en lugar de Luis, lo blanco en vez de los blancos, etc.), o con los sonidos $[d],[s]$ y $[r]$. El efecto producido por esta repentina incorporación de la oralidad es el de una desacralización del patrón lingüístico heredado y al mismo tiempo una consagración del coloquialismo que enriquece la literatura colombiana al integrar la idiosincrasia y el habla de clases sociales tradicionalmente consideradas como marginales. Tal es al menos la lectura global que Cabarcas Ortega (2013) ofrece del poemario de Jorge Artel: "por su referencia a la cultura popular negra del Caribe colombiano, muestra cómo, desde los márgenes del mismo campo literario, surgen estrategias discursivas que consolidan y validan expresiones y proyectos estéticos alternativos" (p. 74). Dentro de la gama de recursos empleados por el poeta, Cabarcas Ortega destaca "el uso de un registro lírico no convencional y la reescritura de ciertos motivos ya tradicionales de la poesía negra" (p. 74), estrategias que "dan forma a un locus de enunciación cuya fuerza expresiva es mucho más compleja de lo que se tiende a pensar" (p. 74). Que tales estructuras, por lo demás comunes a otras áreas geográficas, procedan preferentemente de la cultura popular invita a una reconsideración desapasionada del sistema de valores que nuestras sociedades tienden a asumir como modelos incuestionables.

En definitiva, puede decirse que el poemario Tambores en la noche es una muestra de la revolución poética que Jorge Artel emprendió junto a otros destacados poetas colombianos de la primera mitad del siglo xx, en un contexto nacional e internacional que apelaba a una revisión profunda de los sistemas erigidos por las culturas dominantes. Sublevarse significaba entonces para Artel un gesto de coraje, puesto que no solo exigía superar las dificultades materiales típicas del escritor 
afrocolombiano y de la frágil industria editorial, ${ }^{10}$ sino que también conllevaba el hecho de exponerse a la reacción adversa, frente a una sociedad racista. Pero si parte del reto estribaba en la negativa mirada racial, alimentada por el prejuicio social que acompaña generalmente al escritor “de color” y sus problemáticas inherentes, también había otro desafío estético: llegar a ser original entre tanto conformismo, tomando a contrapelo las costumbres literarias establecidas en su tiempo, y mantenidas por los epígonos de las modas literarias del momento (modernismo y romanticismo en específico), la censura de la "Academia” y el refinamiento aristocrático de la incipiente élite blanca imperante en Cartagena de Indias. No ha de sorprender, por tanto, que la obra poética de Jorge Artel pasara casi desapercibida entre el público de su época. La divulgación de esta poesía emprendida posteriormente por la crítica y muy en especial más recientemente por iniciativa propia del Ministerio colombiano de Cultura es, pues, un acto de justicia y una incitación a continuar la resistencia que el poeta cartagenero emprendió en vida por medio de la palabra poética.

\section{Referencias bibliográficas}

Artel, J. (2010). Tambores en la noche. Bogotá: Ministerio de Cultura.

Avendaño-Ramírez, M. y Villa-Gómez, J. D. (2017). Arte y memoria: expresiones de resistencia y transformaciones subjetivas frente a la violencia política. Revista Colombiana de Ciencias Sociales 8, pp. 502-535. DOI: http://dx.doi.org/10.21501/22161201.2207 [13.05.2020].

Barriga Monroy, M. L. (2012). El afro-colombiano en la educación musical desde la colonia hasta comienzos del siglo xx. El artista 9, pp. 344-353. Recuperado de: https://bit.ly/2XWRdUX [11.05.2020]

Cabarcas Ortega, M. J. (2013). La figuración poética de la identidad: lo negro en Tambores en la noche de Jorge Artel. Estudios de Literatura Colombiana 32, pp. 73-86. Recuperado de: https://revistas. udea.edu.co/index.php/elc/article/view/16293 [02.01.2020].

Díaz, A. J. (2009). La construcción de lo afro en la poética de Jorge Artel. Cuadernos de literatura del Caribe e Hispanoamérica 9, pp. 95-106. Recuperado de: https://bit.ly/2BUCiBQ [13.12.2019].

Duncan, Q. (2013). El afrorrealismo en Nicolás Guillén y Jorge Artel. Comunicación 22, pp. 4-11, Recuperado de: https://bit.ly/3hqrKuq [20.12.2019].

Erll, A. (2012). Memoria colectiva y culturas del recuerdo. Estudio introductorio. Traducción de Johanna Córdoba y Tatjana Louis, Bogotá: Universidad de los Andes.

10 Como explica Prescott (2000), otro escollo al que se enfrentaba el escritor afrodescendiente colombiano de las clases media y baja era el subdesarrollo de la industria editorial nacional que no facilitaba la publicación y divulgación de sus obras (p. 58). 
Ferrer Ruiz, G. (2010). Prólogo. En J. Artel. Tambores en la noche (pp. 11-40). Bogotá: Ministerio de Cultura.

Gilroy, P. (2014). Atlántico negro. Modernidad y doble conciencia. Madrid: Akal.

González Muñoz,J. (2010). Vaudou: herencia africana en la sangre americana. Memorias de la insurgencia afrovenezolana 2, pp. 19-26. Recuperado de: https://bit.ly/2XxZuxa [02.01.2020].

Jacobo-Marín, D. (2010). El código negro francés y la esclavitud en América. Universitarios potosinos 6, pp. 30-35. Recuperado de: https://bit.ly/3guRDsQ [02.01.2020].

LaRosa, M. J. y Mejía, G. (2013). Historia concisa de Colombia (1810-2013). Bogotá: Editorial Pontificia Universidad Javeriana.

Maglia Vercesi, G. (2005). Estéticas de resistencia en la poesía del Caribe afrohispánico. Cuadernos de Literatura 19,pp. 82-100. Recuperado de: https://bit.ly/2UFcTCH [05.12.2019].

Asante, M. K. (2003). L'Afrocentricité. Paris : Menaibuc.

Nora, P. (2008). Pierre Nora en Les lieux de mémoire. Montevideo: Trilce.

Ocampo Zamorano, A. y Cuesta Escobar, G. (2010). Prólogo. En Antología de mujeres poetas afrocolombianas (pp. 11-59). Bogotá: Ministerio de Cultura.

Prescott, L. E. (2000). Without hatreds or fears. Jorge Artel and the Struggle for Black Literary Expression in Colombia. Detroit: Wayne State University Press.

Sandoval, S. A. (2011). El canto de la sangre: la música en la poesía de Jorge Artel. Todas as Musas 2, pp. 204-218. Recuperado de: https://bit.ly/2MTCUKm [28.11.2019]

Sartre, J. P. (1948). Orphée noir. Dans L. S. Senghor. Anthologie de la nouvelle poésie nègre et malgache de langue française (pp. IX-XLIV). Paris : Presses Universitaires de France.

Senghor, L. S. (1945). Chants d'ombre. Paris : Seuil.

Senghor, L. S. (1956). Éthiopiques. Paris : Seuil.

Valero, S. (2013). ¿De qué hablamos cuando hablamos de "literatura afrocolombiana"? o los riesgos de las categorizaciones. Estudios de Literatura Colombiana 32, pp. 15-37. Recuperado de: https:// revistas.udea.edu.co/index.php/elc/article/view/16290 [11.05.2020]

Valero, S. (2015a). Introducción. Literatura y ‘Afrodescendencia’: identidades políticas en la literatura afrolatinoamericana del siglo xxi. Revista de crítica literaria latinoamericana 81, pp. 9-17. Recuperado de: https://www.jstor.org/stable/44475374 [12.05.2020].

Valero, S. (2015b). La construcción del "sujeto afrodiaspórico" como sujeto político en Un mensaje de Rosa (2004) y El pueblo afrodescendiente (2012), de Quince Duncan. Revista de crítica literaria latinoamericana 81, pp. 83-107. Recuperado de: https://bit.ly/2YyIY0p [12.05.2020].

Vargas, N. (2005). Aproximación al problema de las literaturas de minorías. Mujeres, negros e indígenas en el mapa historiográfico de la literatura colombiana. Lingüistica y Literatura 47/48, pp. 115-133.

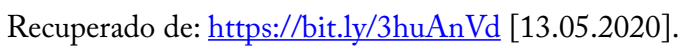

